\title{
Preventing Disability Among Working Participants in Kansas' High-risk Insurance Pool: Implications for Health Reform
}

\author{
Jean P. Hall ${ }^{*}$ and Janice M. Moore \\ Division of Adult Studies \\ University of Kansas
}

Greg W. Welch

Nebraska Center for Research on Children, Youth, Families and Schools

University of Nebraska

\author{
* Corresponding Author \\ Dr. Jean P. Hall \\ 1122 West Campus Road, Rm 517 \\ Lawrence, KS 66045-3101 \\ Phone: 785-864-7083 \\ Fax: 785-864-7799 \\ Email: jhall@ku.edu
}

Published in: 2011, Journal of Vocational Rehabilitation, DOI: 10.3233/JVR-2010-0540

\section{Acknowledgment}

This study was funded by the Kansas Health Policy Authority through a grant from the U.S. Department of Health and Human Services, Centers for Medicare and Medicaid Services (no. 11-P-92389/7-01). 


\begin{abstract}
Health conditions that prevent individuals from working full time can restrict their access to health insurance. For people living in the 35 states that offer high-risk pools, coverage is available but premiums are $125-200 \%$ of standard rates. Additionally, high cost-sharing means enrollees often defer needed care because they must pay large amounts out of pocket. Lack of access may lead to poor health outcomes and disability. The Kansas DMIE investigated whether improving insurance coverage for such a group would improve their health status and reduce their risk of transition to full Social Security disability. Half of the 508 participants received enhanced benefits and nurse case management, the other half received usual risk pool coverage. Outcomes were measured through telephone surveys, focus groups, and claims analysis. Utilization of services increased and health status stabilized for the intervention group, while health status of the control group significantly declined. These findings have broad implications because some plans to be offered under the Patient Protection and Affordable Care Act of 2010 (P.L. 111-148) have similarly high out-of-pocket costs. Considering the long-term cost of full disability, providing adequate health insurance benefits for individuals at high risk of disability may be cost effective.
\end{abstract}

\title{
1. Introduction
}

People with chronic illnesses who are self-employed or work part time to accommodate their chronic conditions usually do not have access to employer-based group health insurance, and are unable to access individual coverage because of their pre-existing health conditions. Although some of them currently access safety net coverage through one of 35 state high-risk pools, historically the high cost of coverage has limited enrollment to a small fraction of those who are eligible. 
Little is known about the extent of disability in the state high-risk pool population; most states gather only the most basic demographic information, such as age and gender, and few gather data on employment. High-risk pool beneficiaries in one state transitioned to Social Security disability programs at a rate eight times that of the general population [8]. As front line workers for people at risk of disability, vocational rehabilitation (VR) professionals need to understand how plans with low actuarial value, which frequently have high premiums and cost sharing, influence work and health outcomes. The Kansas Demonstration to Maintain Independence and Employment (DMIE) tested whether disability can be prevented or forestalled by supplementing such a plan with a wrap-around package of Medicaid-like benefits and subsidized premiums. In this paper we compare medical costs and utilization, delays in accessing medical care, physical well-being, and work outcomes for a sample of adults enrolled in the Kansas high-risk insurance pool with and without supplemental DMIE benefits.

\section{Background and Literature Review}

\subsection{High-risk health insurance pools.}

Approximately 200,000 people are currently enrolled in state high-risk pools [5].

Although each state pool is unique, most generally follow a model benefits structure outlined for pools by the National Association of Insurance Commissioners (NAIC). These plans charge a higher premium than prevailing individual market rates (typically $125 \%$ to $200 \%$ of standard risk, local market rates) that increases with age [12]. According to the Government Accountability Office (GAO), in the 5 states that collect these data, the a verage enrollee is 49 years old - indicating that enrollees' rates are skewed toward the higher end of the rate scales $[5]$.

Most states offer a choice of several high-risk pool plans with varying deductible levels; 
the majority have a minimum annual deductible of either $\$ 500$ or $\$ 1,000$, with some going as high as $\$ 15,000$. Plans with higher deductibles have lower monthly premiums and, therefore, tend to attract less affluent individuals. The average household income of high-risk pool enrollees in the 5 states that reported these data is $\$ 41,000$, an income level at which high deductible plans are likely to be the only affordable option [5]. Unfortunately, the result is that these individuals are unlikely to receive any meaningful health care benefit other than protection against catastrophic loss, and those who utilize care may experience medical debt.

The Patient Protection and Affordable Care Act (PPACA) of 2010 (P.L. 111-148) created a new temporary national high-risk pool that is administered at the state level either by state agencies or a third party administrator under contract with the U.S. Department Health and Human Services (DHHS). To be eligible, individuals must have been uninsured for at least 6 months, must be citizens, and must have a pre-existing condition that resulted in a denial of coverage in the individual market. The federal high-risk coverage, called the Pre-existing Condition Insurance Plan (PCIP), may be more affordable than state pools because premiums are set at standard rates, allowing rates to vary from older to younger beneficiaries by a maximum of 4 to 1 . However, no federal subsidy is available to reduce cost-sharing, so these plans may be more expensive for lower-income consumers than those that will be offered in the state exchanges that become available to all individuals in 2014. In addition, the annual out-of-pocket maximum for participants in many cases will be $\$ 5,950$, the current level for health savings accounts. To date, 27 states administer their own pools, while 23 others and the District of Columbia have plans administered by the federal government. The structure of state administered plans varies from state to state and from the federally administered plan. The PPACA mandates that actuarial values may be no lower than $65 \%$, which means that on average 
they must cover at least $65 \%$ of health costs. Similarly, the Bronze (that is, basic or entry-level) plans that will be available to all Americans through the health insurance exchanges in 2014 will have minimum actuarial values of $60 \%$.

Existing state high-risk pools provide insights into the potential effects of the national pool. The Government Accountability Office found that less than 5\% of the nation's eligible uninsured population enrolls in state high-risk pools [5]. Further, GAO researchers confirmed that premiums and deductibles are much higher, coverage is less generous, and annual and lifetime caps on coverage are much more common than in typical employer-based plans. Such health insurance may not provide adequate coverage for those with very expensive chronic conditions, who are most in need of services.

\subsection{Economic barriers to health care access.}

Simply having insurance does not mean that individuals have access to needed health care. Several recent studies found that when a health insurance beneficiary bears a greater financial risk (i.e., deductibles, co-payments), he or she is more likely to be discouraged from using needed medical services, potentially resulting in poor long-term health outcomes $[2,6,8$, 10, 21]. Medical debt can also be an access barrier. For example, Seifert and Rukavina found that $15 \%$ of people with health insurance reported having medical debt, and $70 \%$ of these individuals said they incurred their debt while they were insured [16]. Even with health insurance, this debt made them more likely to not fill prescriptions, not see specialists, and skip needed tests, treatments, or follow-up care.

Declining health can lead to decreased work performance and, ultimately, inability to sustain gainful employment. People with chronic conditions who forgo needed care may progress more rapidly toward disability and, potentially, a lifetime of reliance on government 
assistance $[2,6,8,10,21]$. Honeycutt found that people who lacked health insurance had an increased likelihood of progressing to federal disability [9]. On the other hand, Hadley estimated that improving an individual's health status from "fair to poor" to "good to excellent" would increase both work effort and earnings by approximately $15 \%$ to $20 \%$, increase incomes and tax revenues, and reduce government spending for disability and other health-related programs [7]. Loeppke and colleagues reported that employers were increasingly aware that if they cut shortterm costs of medical coverage, the result could be much greater long-term costs in lost productivity [11]. In fact, they found that the costs of health-related lost productivity were more than four times greater than medical and pharmacy costs.

For people with disabilities or potentially disabling conditions, economic barriers to health care access or lack of coverage are intertwined with their employability and independence. As one focus group participant enrolled in the Kansas demonstration project observed,

"We're in a 'Catch-22': If you can't get your health better because the insurance doesn't cover services, then you can't get a fulltime job, so then you can't get good insurance to help get your health better" [8, p. 349].

\subsection{Intervention description.}

The Centers for Medicare and Medicaid Services (CMS) are concerned about escalating enrollments into the federal disability system and associated health care programs, Medicare and Medicaid, which more than doubled from 4 million in 1985 to more than 10 million in 2007 [19]. As part of the Ticket to Work and Work Incentives Improvement Act (P.L. 106-170), in 2005 CMS awarded demonstration grants to four states to test interventions for preventing or forestalling disability. The four states targeted populations with varying types of disability, from major mental illness to diabetes and other physical conditions. The Kansas DMIE was the only 
study targeting state high-risk pool beneficiaries, most of whom have multiple comorbidities. The Kansas DMIE hypothesized that enhancing insurance coverage available through the state high-risk pool could prevent or forestall full Social Security disability among participants with potentially disabling conditions. Specifically, the demonstration intervention provided enhanced high-risk pool coverage with a wrap-around package of benefits and cost-sharing subsidies. Monthly premiums were set at a flat $\$ 152$ (down from an average $\$ 443$ ), all deductibles were eliminated, and participants paid only a \$3 co-pay per service. The DMIE also provided services not normally covered by the state's Medicaid plan for adults, such as dental, vision, and hearing services (including eyeglasses and hearing aids), smoking cessation, obesity management (including gym memberships and dietary counseling), health promotion activities, and vocational rehabilitation and worksite assessment services. Additionally, all DMIE intervention members were assigned a nurse case manager who helped them understand their benefits and navigate the health care system.

\section{Data and Methods}

The study design was a randomized controlled trial with repeated measures using medical claims and survey data, including scales such as the SF-12v2 and other researcher-designed items related to medical debt and access to care. We tested for significant between-group differences in service costs and proportion of the group accessing various categories of medical services; and we performed growth curve modeling to assess simultaneous changes within all participants over time, treatment status (intervention vs. control), and the interaction of time and treatment status.

The University of Kansas Human Subjects Committee, which is the University's federally recognized institutional review board, approved this study. The committee is guided by 
the ethical principles regarding all research involving humans as subjects, as set forth in the report of the National Commission for the Protection of Human Subjects of Biomedical and Behavioral Research. Further, HIPAA privacy standards were observed in all aspects of the study.

\subsection{Study Sample}

The Kansas high-risk pool provided an easily accessible and appropriate study population. Eligibility criteria were: (a) at least six months of membership in the state's highrisk pool, (b) age 18 to 60 (this upper age limit excluded individuals who would begin receiving Medicare benefits during the study timeframe), (c) working at least 40 hours per month, and (d) experiencing a potentially disabling health condition based on conditions listed in Social Security Administration Blue Book guidelines [18].

Program evaluators oversaw recruitment and enrollment in the study. The high-risk pool third-party administrator contacted all high-risk pool beneficiaries who met the study's age requirement by letter and telephone; interested parties were invited to complete an application form, verify recent employment by submitting a pay stub or income tax return, and sign an informed consent granting researchers permission to verify their health conditions from high-risk pool claims data. In some cases, when an applicant's health conditions were not verifiable through claims, the study accepted a physician statement instead. Three rounds of recruiting produced 508 participants, which equated to $57 \%$ of the eligible pool during the study period. From this total sample, 412 individuals provided sufficient data for the present analysis, while the remaining participants were dropped from the study because they terminated high-risk pool coverage, sometimes because of cost; obtained other coverage; moved out of state, thus 
becoming ineligible for the state pool; or died during the study period. Participants were randomly assigned to either the intervention $(n=214)$ or control group $(n=198)$.

No significant demographic differences existed between the intervention and control groups at baseline (Table 1). The average participant age was 51 years, half were female, $56 \%$ were married, and $61 \%$ lived in an urban community. The study sample was more highly educated than the general population, with $80 \%$ attending at least some college, and more than half holding an undergraduate or graduate degree. As a condition of the study, all participants had at least one major potentially disabling condition. Based on participant claims from the prior year provided by the third-party administrator of the high-risk pool and self-reported conditions, the four most prevalent co-morbidities were musculoskeletal (52\%), psychiatric (36\%), cardiovascular (32\%) and diabetes/endocrine (29\%) conditions (Table 2).

\section{Table 1}

Demographics by Intervention and Control Groups

\begin{tabular}{lllc}
\hline & Intervention & Control & Total \\
\hline Age (average at time of enrollment) & 51.0 years & 51.4 years & 51.2 years \\
Female (\% of group) & & & \\
Married (\% of group) & 49.5 & 50.5 & 50.0 \\
Urban residence (\% of group) & 57.5 & 54.5 & 56.1 \\
Educational attainment (\% of group) & 58.9 & 63.1 & 60.9 \\
$\quad$ High school or less & 21.5 & & \\
$\quad$ Some college & 40.2 & 16.7 & 38.2 \\
$\quad$ 4-year degree & 18.2 & 24.7 & 21.4 \\
$\quad$ More than 4-year degree & 20.1 & 22.2 & 21.1 \\
\hline
\end{tabular}


Table 2

Major Potentially Disabling Conditions by ICD-9 code for Total Sample

\begin{tabular}{|c|c|c|c|c|c|c|}
\hline \multirow[b]{2}{*}{ ICD-9 category (codes) } & \multicolumn{2}{|c|}{$\begin{array}{l}\text { Claims-based } \\
\text { conditions }\end{array}$} & \multicolumn{2}{|c|}{$\begin{array}{l}\text { Self-reported } \\
\text { conditions }\end{array}$} & \multicolumn{2}{|c|}{$\begin{array}{l}\text { Maximum } \\
\text { combined }\end{array}$} \\
\hline & $\begin{array}{l}\text { Percent of } \\
\text { group }\end{array}$ & $n$ & $\begin{array}{l}\text { Percent of } \\
\text { group }\end{array}$ & $n$ & $\begin{array}{l}\text { Percent of } \\
\text { group }\end{array}$ & $n$ \\
\hline Immune $(042,279)$ & 1.7 & 7 & 1.7 & 7 & 2.2 & 9 \\
\hline $\begin{array}{l}\text { Cancers }(140-165,170-72,174- \\
77,179-208,230-35)\end{array}$ & 13.1 & 54 & 15.8 & 65 & 18.7 & 77 \\
\hline Diabetes/Endocrine $(250,277)$ & 25.0 & 103 & 25.5 & 105 & 28.6 & 118 \\
\hline Blood (282-289) & 7.0 & 29 & 2.7 & 11 & 8.0 & 33 \\
\hline Psychiatric (294-301, 310-11) & 17.2 & 71 & 33.5 & 138 & 36.4 & 150 \\
\hline $\begin{array}{l}\text { Neurological (331-337, 340-45, } \\
350-59)\end{array}$ & 10.7 & 44 & 10.9 & 45 & 16.3 & 67 \\
\hline Stroke (430-38) & 2.7 & 11 & 1.7 & 7 & 3.2 & 13 \\
\hline Sensory $(360-65,369,386-88)$ & 7.0 & 29 & 3.6 & 15 & 9.7 & 40 \\
\hline $\begin{array}{l}\text { Cardiovascular }(393-98,410- \\
17,420-29,440-48)\end{array}$ & 22.8 & 94 & 25.5 & 105 & 31.6 & 130 \\
\hline Respiratory $(491-96,500-04)$ & 8.3 & 34 & 18.2 & 75 & 19.9 & 82 \\
\hline $\begin{array}{l}\text { Gastrointestinal (555-56, 570- } \\
73)\end{array}$ & 4.1 & 17 & 8.3 & 34 & 9.7 & 40 \\
\hline Renal (580-89) & 1.5 & 6 & 1.7 & 7 & 2.7 & 11 \\
\hline $\begin{array}{l}\text { Musculoskeletal (710-25, 731- } \\
32,737,741)\end{array}$ & 34.5 & 142 & 37.4 & 154 & 51.9 & 214 \\
\hline
\end{tabular}

Although the study required a minimum of 40 hours per month employment, individuals averaged 148 work hours in the month prior to entering the study (Table 3). Participants' average annual income was $\$ 48.0 \mathrm{~K}$, with wide variation between individuals as evidenced by a standard deviation of $\$ 59.8 \mathrm{~K}$, and a median of $\$ 30.0 \mathrm{~K}$. Participants' families averaged total 
annual incomes of $\$ 70.7 \mathrm{~K}(S D=\$ 70.6 \mathrm{~K}, M d n=\$ 50.0 \mathrm{~K})$, which included the participants' own income.

Even as the sample had middle class income levels, they tended to enroll in high-risk pool plans with high deductibles (Table 4). Only $20 \%$ of the sample enrolled in plans with $\$ 500$ to $\$ 1,000$ deductibles while $28 \%$ enrolled in plans with $\$ 5,000$ deductibles. When considered in light of the definitions of underinsurance, $72 \%$ of the sample was underinsured in the high-risk pool before entering the study [15]. Specifically, more than half had deductibles that exceeded $5 \%$ of family income and more than a third had out-of-pocket expenditures greater than $10 \%$ of family income. Additionally, at baseline $29 \%$ of the sample reported medical debt.

\section{Table 3}

Employment and Income by Intervention and Control Groups

\begin{tabular}{|c|c|c|c|}
\hline & Intervention & Control & Total \\
\hline Mean $(S D)$ work hours in prior month & $146.5(86.0)$ & $149.2(76.5)$ & $147.8(81.5)$ \\
\hline Self-employed (\% of group) ${ }^{a}$ & $68.9 \%$ & $73.6 \%$ & $71.1 \%$ \\
\hline \multicolumn{4}{|l|}{ Full time equivalency ( $\%$ of group) } \\
\hline Full time (160 hours or more) & $42.5 \%$ & $52.0 \%$ & $47.1 \%$ \\
\hline Half to full time (80-159 hours) & $40.7 \%$ & $29.3 \%$ & $35.2 \%$ \\
\hline Less than half time (40-79 hours) & $16.8 \%$ & $18.7 \%$ & $17.7 \%$ \\
\hline \multicolumn{4}{|l|}{ Own annual earned income $(\$ \text { in } 000)^{b}$} \\
\hline Mean $(S D)$ & $\$ 46.3(55.5)$ & $\$ 49.8(64.2)$ & $\$ 48.0(59.8)$ \\
\hline $5 \%$ trimmed mean & $\$ 38.2$ & $\$ 40.7$ & $\$ 39.4$ \\
\hline Median & $\$ 30.0$ & $\$ 32.0$ & $\$ 30.0$ \\
\hline \multicolumn{4}{|l|}{ Family annual total income $(\$ \text { in } 000)^{c}$} \\
\hline Mean $(S D)$ & $\$ 69.3(69.1)$ & $\$ 72.2(72.4)$ & $\$ 70.7(70.6)$ \\
\hline $5 \%$ trimmed mean & $\$ 60.9$ & $\$ 63.2$ & $\$ 62.0$ \\
\hline Median & $\$ 50.0$ & $\$ 50.0$ & $\$ 50.0$ \\
\hline
\end{tabular}




\section{Table 4}

Insurance Plan, Underinsurance, and Medical Debt at Baseline (percent of group)

\begin{tabular}{lrrr}
\hline & Intervention & Control & Total \\
\hline Plan deductible at baseline & 1.4 & 3.0 & 2.2 \\
$\$ 500$ & 18.7 & 16.2 & 17.5 \\
$\$ 1,000$ & 20.6 & 24.7 & 22.6 \\
$\$ 1,500$ & 10.7 & 11.6 & 11.2 \\
$\$ 2,500$ & 28.0 & 28.3 & 28.2 \\
$\$ 5,000$ & 19.2 & 15.2 & 17.2 \\
$\$ 7,500$ & 1.4 & 1.0 & 1.2 \\
$\$ 10,000$ & & & \\
Criterion for under-insurance ${ }^{\mathrm{a}}$ & 54.6 & 52.1 & 53.4 \\
Deductible $>5 \%$ of family income & 40.5 & 35.9 & 38.3 \\
Out-of-pocket expenditures $>10 \%$ of family income & 75.6 & 68.8 & 72.3 \\
$\quad$ Either of the above & 27.1 & 30.5 & 28.7 \\
Medical debt & & & \\
\hline
\end{tabular}

Notes: ${ }^{a} n=397$ because of 15 refusals to disclose family income; ${ }^{b}$ Question administered in Round 2 survey, 8 months after study began.

Notes: ${ }^{\mathrm{a}} n=388,24$ people did not answer question; ${ }^{\mathrm{b}} n=401,11$ people refused to disclose own income; ${ }^{c} n=397,15$ people did not know or refused to disclose family income.

This sample may not generalize to the entire high-risk pool because the DMIE program excludes $37 \%$ percent of the pool who were people under 18 or over 60 years of age. The study also excludes people who lacked a potentially disabling condition, and those not working at least 40 hours per month. The sample thus represents a balance between the relatively healthier and relatively sicker beneficiaries.

The sample, however, reflects a substantial and important subpopulation of high-risk pool participants in Kansas as well as in other state pools. All other state high-risk pools target this 
same population of middle- to high-income non-elderly individuals with uninsurable conditions $[14,17]$. As previously mentioned, the GAO reported that the average risk pool member nationally is about 49 years old with an annual household income of $\$ 41 \mathrm{~K}$, and about half of risk pool beneficiaries are employed [5].

\subsection{Data and Instruments}

\subsubsection{Medical claims data}

The third-party administrator of the high-risk pool provided claims data for each participant on a quarterly basis. These data were grouped into seven claims categories: (a) hospitalization, (b) prescriptions, (c) diagnostic/preventive, (d) surgeries, (e) office visits, (f) mental health care, and (g) medical equipment. For purposes of comparability, we included only categories of care that were provided within the original state high-risk pool plan. Supplementary categories such as dental and vision were not included in the intervention group totals because the control group did not have coverage for these services through the high-risk pool.

\subsubsection{SF-12 Physical component summary (PCS)}

The SF-12v2 survey is recognized as one of the more valid measures of health status, and includes a summary score that describes physical health, referred to as the PCS (Physical Component Summary). All SF-12v2 scores are normed to 50 for the general population, which allows researchers to compare the study populations with others in the general population as well as to each other. Scales for four domains within the PCS, which we used in this analysis, describe (a) physical functioning, (b) physical roles, (c) bodily pain, and (d) general health. This instrument was administered to each participant at baseline and repeated either 2 or 4 additional times (every 8 months), depending on how long the participant was in the study (recruiting cohorts 1 and 2 repeated measures $=4$; cohort 3 repeated measures $=2$ ). 


\subsubsection{Other survey elements}

The telephone survey included not only demographic and socio-economic information, but also questions provided by The Access Project, which probed for information about medical debt and its effect on participants' access to care [13].

\subsection{Analytic Approach}

\subsubsection{Medical claims data}

To measure the cost effects of the intervention, we calculated per member per month, or average per month, claims costs for the year prior to enrollment and the first full year of the intervention. This metric was used rather than annual costs because the participants were recruited in 3 cohorts resulting in differing lengths of participation in the study. We also calculated the proportion of participants who filed claims, including breakdowns by type of service. We tested each statistic for significant differences between intervention and control groups during each time period and for each category of claims at $p<=.05, p<=.01$, and $p<=$ .001 .

\subsubsection{SF-12 Physical component summary (PCS)}

As an initial step in understanding the physical health effects of the interventions, we visually inspected PCS trends over time by plotting the average scores for intervention and control groups (Figure 1). We also conducted a repeated measures within-subjects design ANOVA, which showed significant decline $(F=5.422, d f=4, p<.001)$ in the control group scores and little change in the intervention group scores. A plot of individual participant PCS scores revealed slight differences in the rate and shape of the individual trajectories of change, but limitations of repeated measures ANOVA did not allow for a formal statistical test of 
possible differences. Thus, an advanced growth modeling approach was utilized to test for individual differences in the trajectories of change [4].

\section{Figure 1}

Repeated Measures of Physical Component Summary Scores over 32 months by Intervention and Control

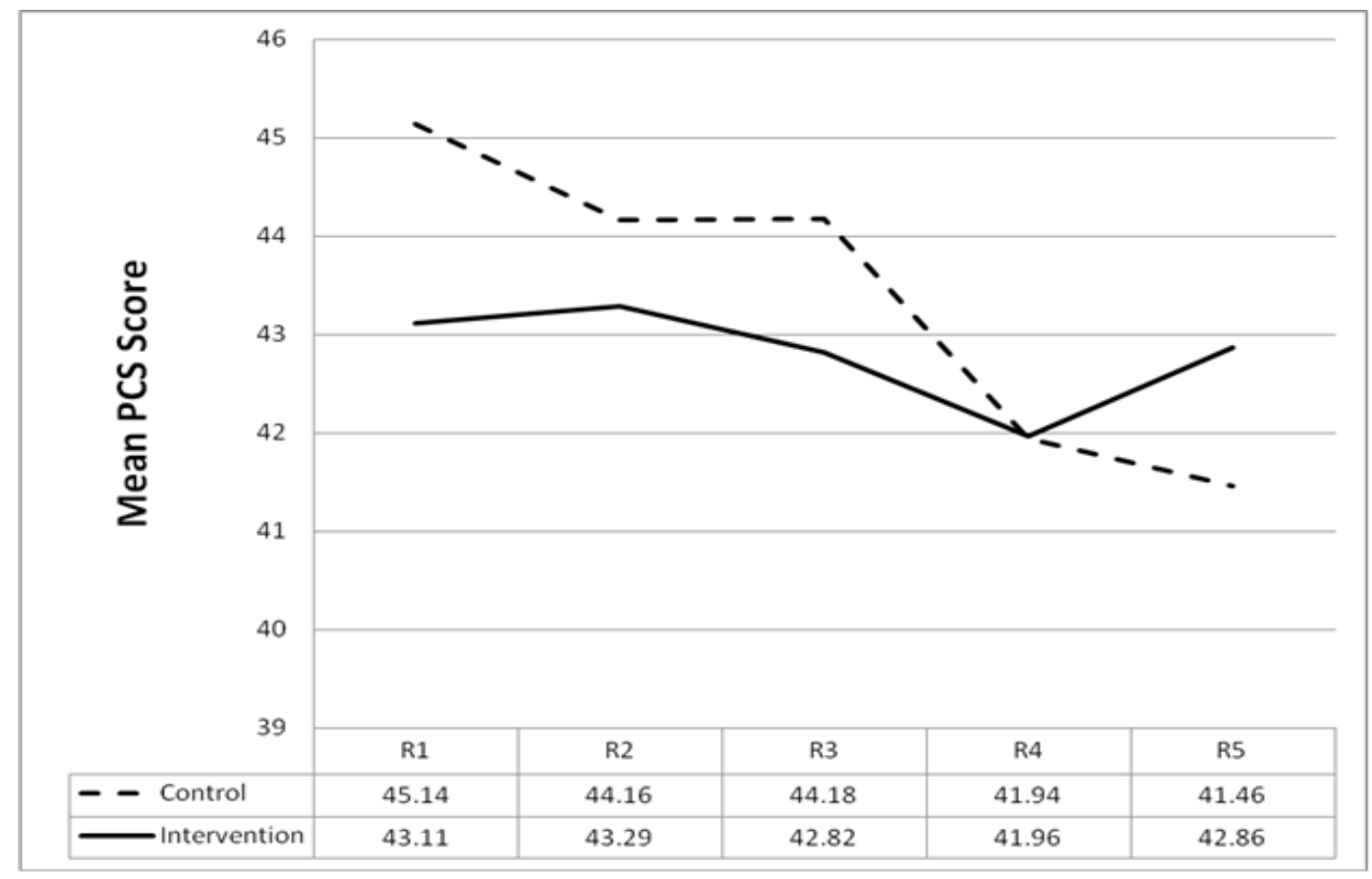

The growth modeling approach utilized included two levels: (a) Level 1, a within-person model of variation in PCS over time; and (b) Level 2, a between-person model of variation in PCS across subjects. We fit the data from the whole sample to three linear models of change. Model 1 is the unconditional means model with no predictors, which is presented for comparison purposes only. Model 2 is an unconditional linear growth model consisting of significant fixed and random effects for the intercept and slope parameters, which represents the rate of change over time. Model 3 is a conditional linear growth model with treatment status (i.e., intervention vs. control) included as a predictor of change. Models were assessed according to multiple goodness-of-fit indices (i.e., -2 Restricted Maximum Likelihood [-2RLL] and Akaike 
Information Criterion [AIC]), while significance of parameter estimates were tested at multiple levels (i.e., $p<=.10, p<=.05$, and $p<=.01$ ).

\section{Findings}

\subsection{Medical costs and access}

The effects of the DMIE intervention are evident in the significantly greater proportion of intervention group members who were served after enrolling in the study, yet at only moderately higher average cost per person for comparable services (Table 5). During the baseline period, intervention and control group members had similar average monthly claims and used medical services in about the same proportion, with the exception of significantly higher control group claims for surgeries - a category that is easily skewed by even a single major procedure, such as an organ transplant. During the first year of the study, greater proportions of intervention than control group members accessed medical services overall and in six of seven claims categories, the exception being mental health care. For example, only $86 \%$ of control group members had claims for office visits compared to $98 \%$ of the intervention group. Likewise, only $80 \%$ of control group members filed claims for prescriptions compared to $96 \%$ of intervention group members.

Even with this greater access to medical care, the average total monthly claims cost per member for comparable services was only moderately higher for intervention $(M=\$ 1,161)$ compared to control $(M=\$ 879)$, which is a non-significant difference (Table 5). In addition, the intervention group averaged significantly higher claims costs in only in two categories_-office visits and medical equipment - both of which are relatively small contributors to total cost compared to the other claims categories. 
Table 5

Differences between Intervention and Control Groups' Allowed Claims Monthly Cost per Member and Proportion of Members Served at Baseline and Year 1

\begin{tabular}{|c|c|c|c|c|c|c|}
\hline \multirow[b]{2}{*}{$\begin{array}{l}\text { Claims } \\
\text { category }\end{array}$} & \multicolumn{3}{|c|}{ Baseline } & \multicolumn{3}{|c|}{ Year 1} \\
\hline & Intervention $^{\mathrm{a}}$ & Control $^{\mathrm{b}}$ & Difference & Intervention $^{\mathrm{a}}$ & Control $^{\mathrm{b}}$ & Difference \\
\hline & \multicolumn{6}{|c|}{ Proportion served } \\
\hline Hospitalization & 36.4 & 39.4 & 3.0 & 57.0 & 39.4 & $17.6^{* * *}$ \\
\hline Prescriptions & 80.4 & 77.8 & 2.6 & 95.8 & 79.8 & $16.0^{* * *}$ \\
\hline $\begin{array}{l}\text { Diagnostic or } \\
\text { preventive }\end{array}$ & 86.9 & 87.9 & -1.0 & 96.7 & 87.9 & $8.8^{* * * *}$ \\
\hline Surgeries & 47.7 & 49.5 & -1.8 & 54.7 & 42.4 & $12.3^{* *}$ \\
\hline Office visits & 88.8 & 84.3 & 4.5 & 97.7 & 86.4 & $11.3^{* * * *}$ \\
\hline $\begin{array}{l}\text { Mental health } \\
\text { care }\end{array}$ & 12.6 & 18.7 & -6.1 & 23.4 & 18.2 & 5.2 \\
\hline $\begin{array}{l}\text { Medical } \\
\text { equipment }\end{array}$ & 9.8 & 9.6 & 0.2 & 18.2 & 6.6 & $11.6^{* * *}$ \\
\hline \multirow[t]{2}{*}{ Total } & 96.3 & 92.4 & 3.9 & 100.0 & 94.9 & $5.1^{* * *}$ \\
\hline & \multicolumn{6}{|c|}{ Average monthly claims $(\$)^{\mathrm{c}}$} \\
\hline Hospitalization & 277.30 & 302.40 & -25.10 & 320.13 & 277.61 & 42.52 \\
\hline Prescriptions & 187.68 & 204.99 & -17.31 & 275.27 & 200.14 & 75.13 \\
\hline $\begin{array}{l}\text { Diagnostic or } \\
\text { preventive }\end{array}$ & 138.47 & 139.56 & -1.09 & 216.02 & 180.07 & 35.95 \\
\hline Surgeries & 70.85 & 145.36 & $-74.51^{*}$ & 185.53 & 115.26 & 70.27 \\
\hline Office visits & 34.54 & 34.78 & -0.24 & 54.74 & 32.26 & $22.48^{* * *}$ \\
\hline $\begin{array}{l}\text { Mental health } \\
\text { care }\end{array}$ & 10.86 & 28.00 & -17.14 & 16.60 & 27.22 & -10.62 \\
\hline $\begin{array}{l}\text { Medical } \\
\text { equipment }\end{array}$ & 7.61 & 4.70 & 2.91 & 18.76 & 5.42 & $13.34^{*}$ \\
\hline Total & 759.62 & 921.53 & -161.91 & 1160.81 & 879.52 & 281.29 \\
\hline
\end{tabular}

Notes: ${ }^{\mathrm{a}}$ Intervention $\boldsymbol{n}=\mathbf{2 1 4}$; ${ }^{\mathrm{b}} \mathrm{Control} \boldsymbol{n}=198$; ${ }^{\mathrm{c}}$ Average monthly claims represents a per member per month cost that was computed as [total claims for the year] / [sum of members enrolled each month]. p $<=.05^{* * *}$ p $<=.01 * * * * *=.001$

\subsection{Delays in accessing medical care}

After 8 months of participation in the study, participants were asked, "Since the time of your last survey, have you needed but delayed or been unable to get needed care?" Forty-five percent of control group members compared to only $11 \%$ of intervention group members responded affirmatively. 


\subsection{Physical well-being}

The SF12-v2 measure of physical health status, the PCS, showed that over time control group members' average health declined significantly while the intervention group members' health remained essentially stable. Table 6 presents a comparison of three linear growth models fit to the data from the entire sample. All scores are normed to the general population, with 50 representing the national average, and each 10 points one standard deviation from the norm. Model 1, the unconditional means model with no predictors, is provided as a baseline for comparison. This model, with an intercept of $43.43(S E=0.52, p<.01)$, includes only the baseline score for an average subject. Model 2, the conditional model, suggests that the average subject has a baseline PCS score of $44.09(S E=0.53, p<.01)$ that decreases 0.36 points $(S E=$ $0.12, p<.01)$ over the study period. Model 3, the conditional model with treatment status included as a predictor of change, estimates an average baseline PCS score of 43.16 ( $S E=0.93$, $p<.01)$ with a 0.13 points $(S E=0.20)$ decrease over the study period. Both the main effect (treatment $=-1.97, S E=1.07, p<.10)$ and the interaction effect (time by treatment $=0.51, S E=$ $0.25, p<.05)$ are significant. These models indicate that, on average, the control group was actually healthier than the intervention group at baseline, but declined more rapidly over time. In fact, intervention group member scores declined on average less than would be expected due to normal aging in a healthy population of the same age [20].

Goodness-of-fit statistics and the significance of the interaction between time and treatment group suggest that Model 3 fits the data better than Models 1 and 2 as evidenced by the lower-2RLL and AIC values. The change in the log likelihood goodness-of-fit statistic from Model 2 to Model 3 of $6.9(d f=2, p<.05)$ indicates that the fit of the model to the data significantly improves when the main effects of treatment and time by treatment interaction are 
included. Additional models were tested utilizing a variety of time variant (e.g., income) and time invariant (e.g., gender) predictors, but in each case the effect itself was insignificant and/or the interaction effects included in the model were insignificant. In addition, the models presented were deemed to be the most parsimonious.

\section{Table 6}

Parameter Estimates (SE) of Physical Component Summary Scores for All Subjects $(n=412)$

\begin{tabular}{|c|c|c|c|}
\hline & Model 1 & Model 2 & Model 3 \\
\hline \multicolumn{4}{|l|}{ Fixed effects } \\
\hline \multirow[t]{2}{*}{ Intercept } & $43.43 * * *$ & $44.09 * * *$ & $43.16^{* * *}$ \\
\hline & $(0.52)$ & $(0.53)$ & $(0.93)$ \\
\hline \multirow{2}{*}{ Time } & & $-0.36 * * *$ & -0.13 \\
\hline & & $(0.12)$ & $(0.20)$ \\
\hline \multirow[t]{2}{*}{ Treatment } & & & $-1.97 *$ \\
\hline & & & (1.07) \\
\hline \multirow[t]{2}{*}{ Time $\mathrm{x}$ Treatment } & & & $0.51 * *$ \\
\hline & & & $(0.25)$ \\
\hline \multicolumn{4}{|l|}{ Random effects } \\
\hline \multirow[t]{2}{*}{ Intercept } & $101.38 * * *$ & $96.61 * * *$ & $96.41 * * *$ \\
\hline & (7.67) & $(7.57)$ & $(7.56)$ \\
\hline \multirow[t]{2}{*}{ Slope (linear) } & & $1.93 * * *$ & $1.90 * * *$ \\
\hline & & $(0.40)$ & $(0.40)$ \\
\hline \multirow[t]{2}{*}{ Residual } & $37.43 * * *$ & $32.63 * * *$ & $32.62 * * *$ \\
\hline & $(1.39)$ & $(1.37)$ & $(1.37)$ \\
\hline$-2 R L L$ & 13118.2 & 13071.2 & 13064.2 \\
\hline AIC & 13122.2 & 13077.2 & 13070.3 \\
\hline
\end{tabular}

Note: -2RLL=-2 Restricted Maximum Likelihood, AIC = Akaike Information Criterion $* \mathbf{p}<.10 ; * * \mathbf{p}<.05 ; * * * \mathbf{p}<.01$

\subsection{Work productivity}

While more than half of the sample worked less than full time, many reported working more than full time. The high monthly average work hour statistic is skewed by high hours reported by some participants such as small business owners, farmers, and ranchers. The intervention and control groups' average work hours were not significantly different at baseline or subsequently. 


\section{Discussion and Implications for Practitioners}

The PPACA does not require small businesses with fewer than 50 full-time equivalent workers to provide health insurance to their employees. Nor does it penalize large businesses if their part-time employees (those working less than 30 hours per week) use federal credits to purchase insurance coverage through an exchange [3]. Thus, PPACA does not fundamentally change access to employer-based insurance for part-time and/or self-employed workers. The Act does, however, provide guaranteed access to coverage through the exchanges-even for people with pre-existing conditions. The basic, least expensive coverage available through the exchanges will have relatively low actuarial values and, in that respect, will be similar to many existing state high-risk pool plans and to the PCIPs that will operate through 2013. The Kansas DMIE findings, based on the experiences of people enrolled in a state high-risk pool, may therefore be informative of potential experiences of people with chronic conditions who enroll in exchange-based health insurance plans starting in 2014.

High out-of-pocket costs in the form of deductibles, co-insurance and co-pays resulted in underinsurance for the majority of DMIE participants at baseline. As Abraham, DeLeire and Royalty noted, less generous insurance tends to decrease households' medical utilization through a "reverse moral hazard" (p. 1) effect [1]. However, our study documented that, when provided more comprehensive benefits and relieved of excessive cost burdens, participants increased their use of medically-appropriate services and had better long-term health outcomes. In fact, intervention group members significantly increased their use of services that could potentially reduce future costs of care, such as diagnostic and preventive services, and were much less likely to report delays in accessing care due to costs. Although average per member per month costs also increased for these individuals, the increased costs were statistically non-significant. 
Perhaps related to the increased use of services, intervention group members also experienced better long-term health outcomes. On average, for healthy individuals 45 to 64 years of age, the annual decline in PCS scores is expected to be about 0.4 points [20]. Although PCS scores for the intervention group fluctuated slightly from measure to measure, the total range was only 1.15 points over the 3 years of the study (Figure 1), less than the expected 1.2 points age-related decline. In contrast, PCS scores in the control group decreased steadily over the same period, ending 3.86 points lower than they began, or about 3 times the total expected for age-related change. The contrast between groups is vividly apparent in Figure 1. At baseline, control group members appeared slightly healthier, on average, than intervention group members, but the growth curve models demonstrate a significant decline in control group scores both relative to themselves at baseline and to intervention group members over time.

Although the DMIE survey measures did not document a significant change in earnings or hours worked over time for either intervention or control groups, numerous open-ended responses on the telephone surveys indicate that improved health is associated with improved work productivity. As one participant shared,

"As a result of this program I am much healthier today than I was prior to the program. I felt better and therefore I was a better employee. My employer thought so also, because I was offered to go to permanent part-time and was able to be covered [by] their health insurance."

This comment also serves to illustrate the short-sightedness of the U.S. health insurance system, which tends to reward healthier, more economically productive citizens with better, more comprehensive coverage and leave those who are sicker with less desirable and often more expensive coverage. The Kansas DMIE findings indicate that, in comparison to the longer-term 
costs of lost productivity and years of possible reliance on federal disability programs, the shorter-term costs associated with improved coverage may be worth the investment. As health care reform initiatives are implemented, more research is needed to compare the health and disability effects of insurance plans at various levels of cost and coverage.

Even for people like those in this study, who on the surface appear to be good candidates for vocational rehabilitation (e.g., well educated, professionals), the structure of their health insurance can contribute to their progression to disability and participation in federal disability programs. Vocational rehabilitation professionals need to be aware that if they can help people find resources to pay for medically-appropriate services, better health and work outcomes can reasonably be expected, and full disability may be prevented or forestalled. 
References

[1] J. M. Abraham, T. DeLeire, and A. B. Royalty, Moral hazard matters: Measuring relative rates of underinsurance using threshold measures, Health Services Research 45 (2010), 806-824.

[2] S. Braithwaite and A. Rosen, Linking cost sharing to value: An unrivaled yet unrealized public health opportunity, Annals of Internal Medicine 146 (2007), 602-605.

[3] H. Chaikind and C. Peterson, Summary of potential employer penalties under the Patient Protection and Affordable Care Act (PPCA), Congressional Research Service, Washington DC, 2010.

[4] C-P. Chou, P. Bentler, and M. Pentz, Comparisons of two statistical approaches to study growth curves: The multilevel model and the latent curve analysis, Structural Equation Modeling 5 (1998), 247-266.

[5] General Accounting Office (GAO), State High-Risk Health Insurance Pools, GAO-0 9730R, 2009

[6] D. Goldman, G. Joyce, and Y. Zhen, Prescription drug cost sharing: Associations with medication and medical utilization and spending and health, Journal of the American Medical Association 298 (2007), 61-69.

[7] J. Hadley, Sicker and poorer-The consequences of being uninsured: A review of the research on the relationship between health insurance, medical care use, health, work, and income, Medical Care Research and Review 60 (2003), 3S-75S.

[8] J.P. Hall, and J.M. Moore, Does high-risk pool coverage meet the needs of people at risk for disability?, Inquiry 45 (2008), 340-352.

[9] T. Honeycutt, Program and benefit paths to the Social Security Disability Insurance 
program, Journal of Vocational Rehabilitation 21 (2004), 83-94.

[10] Kaiser Commission on Medicaid and the Uninsured, Underinsured in America: Is health coverage adequate? Fact sheet no. 4060, Menlo Park, CA, 2002.

[11] R. Loeppke, M. Taitel, D. Richling, et al., Health and productivity as a business strategy, Journal of Occupational and Environmental Medicine 49 (2007), 712-721.

[12] National Association of State Comprehensive Health Insurance Plans, Comprehensive health insurance for high-risk individuals-A state-by-state analysis, 20th edition, NASCHIP, Burnsville MN, 2006.

[13] C. Pryor and J. Prottas, Playing by the rules but losing: How medical debt threatens Kansans' healthcare access and financial security, The Access Project, Boston MA, 2006.

[14] Robert Wood Johnson Foundation, Do state health insurance risk pools make a difference? (2001) http://www.rwjf.org/reports/grr/019190.htm

[15] C. Schoen, S. Collins, J. Kriss, and M. Doty, How many are underinsured? Trends among U.S. adults, 2003 and 2007, Health Affairs 27 (2008), W298-W309.

[16] R. Seifert and M. Rukavina, Bankruptcy is the tip of a medical-debt iceberg, Health Affairs Web Exclusive February 28 (2006), W89-W92.

[17] S. Stearns, R. Slifkin, K. Thorpe, and T. Mroz, The structure and experience of state risk pools: 1988-1994, Medical Care Research and Review 54 (1997), 223-238.

[18] U.S. Social Security Administration (SSA), Disability evaluation under Social Security (Blue Book - June 2006). SSA Pub. No. 64-039, Washington, DC, SSA, 2006.

[19] U.S. Social Security Administration (SSA), Annual statistical report on the Social Security Disability Insurance Program, 2007, Chart 12. Washington, DC, SSA, 2006. 
[20] J. Ware and M. Koskinski, SF-36 Physical \& mental health summary scales: A manual for users of version 1, 2nd ed., QualityMetric Incorporated, Lincoln RI, 2007.

[21] M. Wong, R. Andersen, C. Sherbourne, R. Hays, and M. Shapiro, Effects of cost sharing on care seeking and health status: Results from the medical outcomes study, American Journal of Public Health 91 (2001), 1889-1894. 